2016-01-01

\title{
Guest editorial: Characterisation of crack tip fields 3
}

Susmel, L

http://hdl.handle.net/10026.1/10508

10.1016/j.jfatigue.2016.03.031

International Journal of Fatigue

All content in PEARL is protected by copyright law. Author manuscripts are made available in accordance with publisher policies. Please cite only the published version using the details provided on the item record or document. In the absence of an open licence (e.g. Creative Commons), permissions for further reuse of content should be sought from the publisher or author. 
Editorial

\section{Guest editorial: Characterisation of crack tip fields 3}

Joint Special Issues of the International Journal of Fatigue (Elsevier) and Fatigue $\mathcal{E}$ Fracture of Engineering Materials $\mathcal{E}$ Structures (Wiley) containing selected and fully peer reviewed papers from the 3rd International Conference on Characterisation of Crack Tip Fields held in Urbino, Italy over 20-22 April 2015.

The advent of full-field experimental techniques capable of measuring crack tip fields across a range of size scales has led to considerable activity in the area of characterisation of crack and notch tip fields. Influences of any plastic enclave on crack tip fields ahead of the crack are maximised during cyclic loading. In the case of a parameter like the stress intensity factor, $K$, which characterises the crack tip field via an elastic approximation, it is not surprising that any set of plasticity-induced circumstances which perturb the assumed crack tip field leads to predictive difficulties. It is therefore still an open question in the prediction of fatigue and fracture performance which parameter, or combination of parameters, for example $G, K, T$, best combines ease of use with predictive capability.

The third international conference in the Crack Tip Fields series was organised by the Italian Group of Fracture (www.gruppofrattura.it). It followed the successful format of the first two conferences, based around a largely invited group of delegates, and allowing sufficient time for useful discussion after each paper and again at the end of the conference. The following points emerged from the discussions as being important to better understanding:

- Combinations of models and experimental techniques are required to make real progress, e.g. linking digital image correlation, computed tomography, electronic speckle pattern interference with improved FE and analytical models of crack tip fields.

- Mixed mode solutions are preferable (but add complexity), e.g. thin compact tension specimens under Mode I loading may buckle, inducing Mode III loads and cracks themselves induce multiaxial stress states.

- Multi-parameter solutions are required, e.g. $G, K, T$, etc.
- Location of crack tip is important and requires sensitivity analyses.

- It would be useful to rationalise the various models involving critical distance, area and volume and develop models that bridge micro- to meso- to macro-scale.

- There is still no certainty about the relative importance of load transfer and magnitude across crack surfaces (so-called crack closure).

- Discontinuities can be mathematically difficult to handle.

The papers selected for these joint Special Issues of the International Journal of Fatigue (Elsevier) and Fatigue \& Fracture of Engineering Materials \& Structures (Wiley) demonstrate a range of research that is already giving detailed consideration to a number of the above aspects.

The next conference in the Characterisation of Crack Tip Fields series is proposed to take place in April or early-May 2017, on the French island of Corsica in the Mediterranean; please diarise this event and full information will be circulated about this in good time.

The Guest Editors hope that this fully peer reviewed overview of current thinking in the area of crack tip fields in relation to fatigue and fracture is of use to the research community.

Guest Editors L. Susmel University of Sheffield, UK

M.N. James University of Plymouth, UK

Y. Hong Institute of Mechanics, Chinese Academy of Sciences, China

F. Iacoviello University of Cassino, Italy

Available online 31 March 2016 